\title{
Necropolítica urbana: o plano Conquista 2040 e o arquétipo do terrorismo de Estado no Sertão da Ressaca
}

Urban Necropolites: the Plano Conquista 2040 and the state terrorism archetype in Sertao da Ressaca

Necropolítica Urbana: el Plano Conquista 2040 y el arquetipo del terrorismo de estado en el Sertao da Ressaca

Fernando Tomás Rodrigues ${ }^{1}$ http://orcid.org/0000-0002-2557-3345

\footnotetext{
${ }^{1}$ Bacharelando em Arquitetura e Urbanismo - Faculdade Maurício de Nassau -Brasil, tomasfernandorodrigues@gmail.com
}

\section{Resumo}

Este artigo trata a necropolítica na perspectiva urbana, compreendendo os discursos dos gestores municipais como mecanismos de manipulação da memória coletiva e integrantes do processo de legitimação da autoridade em um estado de exceção. Discorre acerca de Vitória da Conquista, Bahia, questionando a ocupação colonial contemporânea a partir do Plano Conquista 2040, desenvolvido pela Prefeitura Municipal de Vitória da Conquista em conjunto com a Fundação Escola Politécnica da Bahia e caracterizado pelo Plano Diretor de Desenvolvimento Urbano, Plano Diretor do Distrito Aeroportuário e Agência Reguladora Municipal. Analisa o histórico de urbanização articulando a biopolítica às projeções da identidade social, constatando a fundamentação da soberania no imaginário popular e evidenciando a política de morte enraizada nas dinâmicas do município.

Palavras-chave: Estado de exceção. Biopolítica. Vitória da Conquista.

\begin{abstract}
Discusses necropolitics through an urban perspective, understanding the discourses of municipal managers as mechanisms for the manipulation of collective memory and legitimation of authority in a state of exception process integrants. Therefore, it discusses Vitória da Conquista, Bahia, questioning the contemporary colonial occupation from the Plano Conquista 2040, developed by the Municipality of Vitória da Conquista in conjunction with the Bahia Polytechnic School Foundation and characterized by the Urban Development Master Plan, Airport District Master Plan and Municipal Regulatory Agency. It analyzes the history of urbanization articulating the biopolitics to the projections of social identity, noting the foundation of sovereignty in the popular imagination and highlighting the death policy rooted in the dynamics of the municipality.
\end{abstract}

Keywords: State of exception. Biopolitics. Vitoria da Conquista.

\section{Resumen}


Se ocupa de la necropolítica desde una perspectiva urbana, entendiendo los discursos de los administradores municipales como mecanismos de manipulación de la memoria colectiva e integrantes del proceso de legitimación de la autoridad en un estado de excepción. Por lo tanto, analiza Vitória da Conquista, Bahía, cuestionando la ocupación colonial contemporánea del Plano Conquista 2040, desarrollado por el Ayuntamiento de Vitória da Conquista junto con la Fundación de la Escuela Politécnica de Bahía y caracterizado por el Plan Maestro de Desarrollo Urbano, Plan Maestro del Distrito del Aeropuerto y Agencia Reguladora Municipal. Analiza el proceso histórico de urbanización articulando la biopolítica a las proyecciones de identidad social, destacando los fundamentos de la soberanía en la imaginación popular y destacando la política de la muerte enraizada en la dinámica del municipio.

Palabras clave: Estado de excepción. Biopolítica. Vitoria da Conquista.

Recebido em: 29/11/2019

Aceito para publicação em:28/12/2019

\section{Introdução}

O município de Vitória da Conquista, no Sudoeste Baiano, demonstra-se eixo para a compreensão dos embates de classe nas cidades do interior devido à sua funcionalidade e abrangência enquanto polo regional. Configurada Capital Regional, rede de articulação e concentração de fluxos, as dinâmicas de produção e reprodução do espaço remontam à colonização exploratória portuguesa: de localização estratégica no estabelecimento da comunicação do litoral da Capitania de Ilhéus com o sertão nordestino, as (re)configurações territoriais do município em torno do complexo viárioº refletem relações hierárquicas na disputa pelo controle socioespacial.

O histórico municipal, desde a formação do Arraial da Conquista e a instalação da Imperial Vila da Vitória até a elevação à categoria de cidade e o anunciado Plano Conquista 2040 - caracterizado pelo Plano Diretor de Desenvolvimento Urbano (PDDU), pelo Plano Diretor do Distrito Aeroportuário (PDAP) e criação da Agência Reguladora Municipal (Agervic) - se percebe célula para uma discussão acerca da necropolítica, a política da morte, a partir de uma perspectiva urbana.

O presente ensaio integra uma pesquisa em andamento orientada na análise das ações e discursos dos gestores municipais de Vitória da Conquista, articulando estes com os processos de urbanização do município e os conceitos de necropolítica

\footnotetext{
${ }^{2}$ Anel Rodoviário Jadiel Matos. O município de Vitória da Conquista é cortado por rodovias federais como a BR-116 e BR-415, além das rodovias estaduais BA-262, BA-263 e BA-265;
} 
(MBEMBE, 2016) e estado de exceção (AGAMBEM, 2004) para discorrer acerca do Plano Conquista 2040, desenvolvido pela Prefeitura Municipal de Vitória da Conquista em conjunto com a Fundação Escola Politécnica da Bahia (FEP/BA), partindo do denunciado em As Ilusões do Plano Diretor (VILLAÇA, 2005).

\section{Critérios e analises empregados na elaboração do texto}

A base lógica empregada foi o método materialista histórico-dialético, de procedimentos de pesquisa: com a Supervisão do cronograma de elaboração do PDDU, a partir dos Grupos de Trabalho e Acompanhamento (GTA). A observação dos "espaços participativos" (PMVC, 2019a) - dentre reuniões, audiências públicas, conferências municipais, grupos de bairro/distritos, plenárias por segmento e encontros territoriais se deu como suplente dos membros titulares do GTA composto pela Comissão Institucional de Mobilização do PPDU/PDAP e por representantes de instituições de ensino, associações profissionais e de entidades e lideranças da área urbanística;

I. Seguido por um Estudo da Relação De Produtos Contratuais Entregues (PMVC, 2019b) do Contrato n 019-35/2018, o qual possui "como objeto a elaboração do Plano de Ações Estruturantes Vitória da Conquista 2020 - Etapa I, concebido como um elenco orgânico e estruturado de projetos e ações a serem implementados no período 2017/2020 pela nova Administração Municipal” (PMVC, 2018).

II. A Atualização do mapeamento dos loteamentos, ocupações urbanas e assentamentos populares de Vitória da Conquista, com elaboração cartográfica a partir do trabalho O Urbano em Construção Vitória da Conquista: um retrato de duas décadas (FERRAZ, 2001), que investiga a construção do espaço urbano de Vitória da Conquista entre 1977 e 1996. Com o mapeamento da especulação imobiliária no município e dos fluxos populacionais pós-ações de reintegração de posse no Parque Municipal da Serra do Periperi $^{3}$.

Destarte, em primeiro momento de investigação científica, propõe-se a análise do pronunciamento de abertura proferido pelo prefeito municipal (2016-2020), Herzem Gusmão Pereira, durante a Reunião de Lançamento do Plano Diretor de Desenvolvimento Urbano de Vitória da Conquista (PDDU), em 19 de fevereiro de 2019. Este trabalho é parte de uma reflexão sobre o papel do urbanismo de espetáculo no controle social, atentando para a percepção categórica autônoma do espaço no pensar

\footnotetext{
${ }^{3}$ Unidade de Conservação definida pelo Decreto Municipal no 9.480/99 (PMVC, 2007).

V.3, n.4, Especial, 2019 http://periodicos2.uesb.br/index.php/geo

Este é um artigo de acesso aberto sob a licença Creative Commons da CC BY
} 
histórico. Pesquisas posteriores tratarão dos resultados dos procedimentos especificados de I a IV, partindo das indagações aqui iniciadas, objetivando assim a exposição crítica das diferentes fases de consolidação do Plano Conquista 2040: lançamento, desenvolvimento e execução.

Questiona-se, desta forma, em um "paradigma de governo dominante na política contemporânea" (AGAMBEN, 2004, p. 18), o que representa um "plano técnico, político e social" (PMVC, 2019a) para "resolução de conflitos e pacificação de interesses em disputa" (PMVC, 2019a); o que significa, em uma narrativa de exceção, "preparar uma cidade para seu bicentenário" (PEREIRA, 2019) - a que o prefeito municipal se refere ao afirmar que "a cidade perdeu uma grande oportunidade" (PEREIRA, 2019)? Representam as gestões municipais de Vitória da Conquista uma soberania? Se sim, são os gestores soberanos ou recursos desta? Os discursos dos gestores municipais têm em vista um antagonismo concreto? Alfim, a quem servem os instrumentos da chamada Política Urbana, senão à manifestação do necropoder na ontologia do espaço?

Manhã de 9 de novembro de 1840. Do sertão de Caetité está chegando Joaquim Venâncio de Almeida. Ele vem, da parte do rei, instalar a Imperial Vila da Vitória. João Dias de Miranda, último filho vivo do Coronel João Gonçalves da Costa, conta as sagas da conquista e fundação do arraial: - Meu pai, junto a mim, no combate decisivo, quando os índios, rebelados, ameaçavam-nos vencer, fez uma promessa à Virgem: - se a vitória fôr nossa, ó Nossa Senhora da Vitória, mando fazer uma igreja onde a vossa imagem será louvada para sempre! E naquele instante angustioso, como por milagre, os índios foram cedendo, cedendo, e a vitória ficou de nosso lado. A capela e o povoado foram construídos. Agora, silêncio completo [...] Agora, a Vila está crescendo [...] A cidade progride. Multiplicam-se as casas e as ruas que surgem batizadas pelo povo [...]. Aparecem as avenidas e os bairros que crescem desordenadamente [...] É Conquista que surge [...] nada a detém nesta dança do seu dinâmico destino (TANAJURA, 2000, $)^{4}$.

Na manhã de 19 de fevereiro de 2019. Do auditório do Campus Anísio Teixeira, da Universidade Federal da Bahia (UFBA), em Vitória da Conquista, Herzem Gusmão Pereira explicita a premeditação de um município. Em um cenário político nacional caracterizado pelo sítio constitucional dos princípios de gestão democrática e participação popular, o Plano Conquista 2040, expressa o prenúncio da sublevação do

\footnotetext{
${ }^{4}$ https://www.blogdaresenhageral.com.br/parabens-vitoria-da-conquista-172-anos-de-emancipacaopolitica/ acesso em 10 de novembro de 2019
} 
direito à cidade e as sistematizações socioespaciais traduzem a transição progressiva das sociedades disciplinares para as sociedades de controle (DELEUZE, 1992): a urbe enquanto mecanismo-chave da manipulação social. Não se pode analisar este certame, porém, sem conceber o espaço geográfico na consolidação de um estado de exceção.

\section{Bases conceituais}

Ao ser definido como um conjunto indissociável de sistemas de objetos e sistemas de ações (SANTOS, 2006), o espaço implica na compreensão epistemológica da técnica; na singularidade de suas manifestações, o fenômeno técnico abrange a sociotécnica, a cultura, os sujeitos sociais e sua inter-relação com o espaço geográfico. Não se compreende o espaço sem antes compreender as dicotomias, fluxos correlacionais e estruturas de poder que o produzem e reproduzem. Quando se visualiza o espaço enquanto sistema, entende-se como este é objeto de Estado - o controle das noções de território, povo, sociedade e governo regendo conjunturas sociopolíticas e, consequentemente, precedendo a civilização da violência.

É como traz Giorgio Agambem (2004): não somente o espaço, o corpo biológico dos indivíduos se torna eixo estratégico de controle político. O Estado justifica o sítio do ordenamento jurídico vigente como para a sua própria conservação; o estado de exceção é caracterizado pela suspensão constitucional, pelo esfacelamento dos direitos individuais através da apropriação de supostas situações de crise, emergência, risco iminente; quando exceção e norma se confundem; quando a violência é instaurada com força e identidade de lei e "está incluída no direito por sua própria exclusão" (AGAMBEM, 2004, p.86).

Achille Mbembe (2016, p.128) afirma que “o poder (e não necessariamente o poder estatal) continuamente se refere e apela à exceção, emergência e a uma noção ficcional do inimigo" - o terror relacionado as narrativas de dominação e emancipação. Pressupõe-se a expressão máxima de uma soberania no droit de glaive, o direito soberano de matar. Os corpos são agora dispositivos políticos; é agora conteúdo geográfico do cotidiano a necropolítica (MBEMBE, 2016). Necropolítica não é a morte, mas o poder de decisão sobre a morte; a violência como aparato jurídico-político - as tecnologias de terror; a vigia e punição estatais. O Estado em exceção declarado não só controla a vida, ele decide quem morre. 
O canto da mãe-da-lua gemeu/carregada de maus presságios/e o coração do guerreiro se armou para a luta/as águas do poço escuro tingiram-se de sangue/e uma lua negra rodopiou sobre a tarde nervosa/Eh ehhhhhhhhhhhhhhh!/Um grito de guerra perdurou-se no beiço da floresta/enquanto um enxame de setas assobiava na sanha dos mongoiós/tambores rufaram o macabro balé da morte/e um gemido de dor chegou aos ouvidos de Tupã/despertando os seus mortos!/Mas o facão surdo de João Gonçalves brandiu/traição e partilha no terreiro da sesmaria, assentado com sangue/o registro de nascimento da Imperial Vila da Vitória (JEHOVAH, 2001 apud OLIVEIRA, 2012, p. 1).

Villaça, (2005, p.7), associa os debates públicos dos planos diretores à "violenta desigualdade de poder político e econômico.” Destaca, ao tratar do vaticínio cataclísmico enquanto instrumento de controle de massas, a "desigualdade de poder e a falta de democracia da dita 'Participação Popular' e a diferença entre as participações dos diferentes setores da sociedade" (VILLAÇA, 2005, p. 63). Essa diferença participativa é evidenciada através dos métodos, entre acessos e possibilidades na gestão democrática, sendo a escolha dos problemas crucial na definição dos participantes do debate, "quem pressiona dentro e quem pressiona fora deles" (VILLAÇA, 2005, p. 63). Nesse contexto, questiona-se a criação de uma atmosfera não apenas ilusória, mas alegórica, bíblica ${ }^{6}$, de participação popular no desenvolvimento da "cidade que queremos para o futuro" (PMVC, 2019a) - isto é, o Plano Conquista 2040 enquanto cortina de fumaça da soberania.

O poder - aqui tratando do poder político; o poder em mecânica e concretude (FOUCAULT, 2017) - de sítio perceptivo dos sujeitos sociais em relação à configuração da memória - “oficial”, hegemônica, dominante - no Sertão da Ressaca ${ }^{7}$ advém das projeções de uma narrativa mítica (OLIVEIRA, 2012) desde a instalação da Imperial Vila da Vitória; das projeções do regime de verdade; do regime discursivo e “dos efeitos de poder próprios do jogo enunciativo" (FOUCAULT, 2017, p. 40).

Ao entender como "o processo que gerou a periferia de Vitória da Conquista está intimamente vinculado à relação existente entre os interesses dos loteadores e a permissão de abertura de loteamentos sem infra-estrutura, por parte do poder público municipal" (FERRAZ, 2001, p. 63), demonstrando-se notável a "longa aliança entre os

\footnotetext{
${ }^{5}$ Texto extraído de https://agentediz.com.br/um-poema-para-vitoria-da-conquista-e-sua-homenagemnoturno-de-vitoria-da-conquista-173-anos-de-emancipacao-politica/ acesso em 10 de novembro de 2019

6 "Deus está abençoando, nós estamos trabalhando;" “[...] que Deus nos abençoe e nós vamos avançar" (PEREIRA, 2019). Em Vitória da Conquista, "a civilização por meio da fé [...] foi o fio condutor da tessitura da memória oficial" (OLIVEIRA, 2012, p. 85).

${ }^{7}$ Região que abrange o território do Rio das Contas ao Rio Pardo, tendo Vitória da Conquista como núcleo.

V. 3, n.4, Especial, 2019 http://periodicos2.uesb.br/index.php/geo
}

Este é um artigo de acesso aberto sob a licença Creative Commons da CC BY 
interesses imobiliários e a legislação urbanística” (VILLAÇA, 1986, p. 37) explícita nos Planos Diretores Urbanos de 1976 e 2007, parte-se então para o fio analítico de crítica das políticas públicas municipais enquanto objetos tecnocráticos não de erradicação, mas de manutenção da desigualdade. Observa-se aqui, então, o sujeito em sua constituição na trama histórica: "nas relações citadinas, a vitória de embates, conflitos e lutas cotidianas. Na configuração territorial, a conquista de interesses e necessidades" (FERRAZ, 2001, p.24) - a genealogia da soberania no município através da megalomania.

\begin{abstract}
Veja a Serra do Periperi, olha a chuva de domingo. Eu fiz um apelo e eu vejo aqui o gerente, o superintendente da Caixa Econômica, um grande parceiro, o Ismael Boaventura. Nós fizemos um apelo à Caixa Econômica e outros agentes financeiros que os empreendedores de Conquista parem de construirem na Serra do Periperi. A cidade está toda interviabilizada. Destruíram praticamente que quase toda a vegetação da serra e a cidade está pagando um preço altíssimo em função dessa devastação desordenada. [...] A chamada Praça da Juventude $^{8}[\ldots]$ 'Prefeito, vamos tirar essa quadra daqui' [...] A Caixa Econômica Federal [...] de 45 milhões nós separamos 7 milhões para o parque da cidade. Vamos edificar o parque [...] Esta terra é nossa [...] na Caixa Econômica Federal, no Banco do Brasil, na Receita, na Previdência [...] (INFORMAÇÃO VERBAL) ${ }^{9}$.
\end{abstract}

O que tanto rege quanto simboliza o Plano Conquista 2040, senão os enunciados de poder, senão as formas de hegemonia, senão o terrorismo de Estado como engrenagem neoliberal percavindo a especulação imobiliária da poligonal do Parque Municipal da Serra do Periperi e da Reserva Florestal do Poço Escuro - zonas não somente definidas ${ }^{10}$ como de Adensamento Condicionado/Controlado e Áreas de Preservação Permanente (PMVC, 2007), mas de interesse em evidência constante pela gestão municipal?

Derivada a consciência de que "o controle não só terá que enfrentar a dissipação das fronteiras, mas também a explosão dos guetos e favelas” (DELEUZE, 1992, p.222), é inevitável retomar o episódio de reintegração de posse ocorrido em dezembro de 2017

\footnotetext{
${ }^{8}$ Equipamento urbano localizado entre os bairros periféricos Guarani e Cruzeiro, nas imediações da Reserva Florestal do Poço Escuro, Unidade de Conservação criada pelo Decreto Municipal no 8.696/96 (PMVC, 2007).

${ }^{9}$ Texto extraído do pronunciamento do Prefeito Herzem Gusmão Pereira, Lançamento do Plano Diretor de Desenvolvimento Urbano de Vitória da Conquista (PDDU). Em 25/04/2019, pronunciamento realizado no autidtorio da UFBA, campus Vitória da Conquista

${ }^{10}$ A Lei Municipal no 1.385/2006 define como de Adensamento Controlado as "áreas com problemas de drenagem e declividade e restrições ambientais decorrentes da proximidade com a Serra do Periperi e o Poço Escuro [...]" (PMVC, 2006) e Condicionado as "áreas com características topográficas especiais e restrições ambientais pela proximidade com a Serra do Periperi, carentes de equipamentos urbanos [...]” (PMVC, 2006).
} 
no Parque Municipal da Serra do Periperi - onde, após a demolição das habitações da Ocupação Cidade Bonita, no bairro Nova Cidade, e sob pena de remoção compulsória, os pertences dos ocupantes (atingidos por bombas de efeito moral e balas de borracha pela Polícia Militar) foram carregados pela empresa responsável pela coleta de lixo do município (BARRETO, 2018). A qual Estado reintegra-se tal posse, senão à Imperial Vila da Vitória de João Gonçalves da Costa; senão à "Conquista do futuro" (PEREIRA, 2019) de Herzem Pereira Gusmão; senão à marca da aberração nos corpos políticos do inimigo periférico?

No entanto, a batalha mítica, bem como do banquete da morte, podem ser pensados para compreender a edificação das memórias oficiais conquistenses e a justificativa da posse das terras nativas. Determinar o fim das etnias indígenas do Planalto da Conquista, por meio desses fatos míticos, abriu o caminho para que as famílias descendentes do Capitão-mor João Gonçalves, se tornassem as proprietárias das terras e detentoras do poder político no Arraial da Vitória. Assim, entendo que o "fim" dos índios do Sertão da Ressaca é a ante-sala do esbulho fundiário (OLIVEIRA, 2012, p. 73).

Se, como Santos (2019) afirma, a deflagração de estratégias de controle das massas populares se dá através da difusão do medo, do caos e da desordem, não se percebem, deste modo, os fenômenos de segregação - a falácia do "direito à cidade" em essência - "formas de crueldade mais íntimas, sinistras e tranquilas" (MBEMBE, 2016, p.129) do direito de matar? Não seriam, portanto, os planos diretores municipais operações urbanas consorciadas, por conseguinte, representação-mor da crise das instituições? Isto é, não seria esta a ilustração da "implantação progressiva e dispersa de um novo regime de dominação" (DELEUZE, 1992, p. 226) - do exercício do controle sobre a mortalidade e da definição da vida como implantação e manifestação de poder?

O coro dos mortos se confunde com os ventos da madrugada: Nesta terra da Conquista mata-se por cem-reis-coados e por-dê-cá aquela-palha. Mata-se no claro dia, no escuro das valas ou na noite enluarada. Mata-se por empreitada, por tal preço combinado, a domicílio ou no mato, a prestaço ou fiado. Mas a voz do poeta, que vem da celeste altura, abafa os rumores da noite: - "Conquista, tesouro imenso, o mais belo da Bahia. Tem mais brilho aqui o sol, tem mais amores em teus lares que luzes o arrebol"... (TANAJURA, 2000 apud OLIVEIRA, 2012 p, 1) ${ }^{11}$.

\footnotetext{
${ }^{11}$ Texto extraído de https://agentediz.com.br/um-poema-para-vitoria-da-conquista-e-sua-homenagemnoturno-de-vitoria-da-conquista-173-anos-de-emancipacao-politica/ acesso em 10 de novembro de 2019
} 
Percebe-se, em Vitória da Conquista, como a gestão estratégica da memória evidenciada desde a folclorização das políticas genocidas de interiorização - é essencial no processo de legitimação da autoridade em um estado de exceção por ela própria, fundamentando a violência como parte do cotidiano popular, ao ponto em que se vivencia o modo como a insegurança se materializa na produção social do espaço (SANTOS, 2019) em cenários de opressão, visto a compreensão dos próprios sujeitos sociais de suas trajetórias de marginalização. O demiurgo então se faz soberano manejando um estado distópico na cidade-pesadelo; anunciando o bicentenário do controle social através da manipulação das percepções coletivas de subsistência dos indivíduos. Não obstante, se faz mitológico, validando a exceção por meio do "banquete da morte" 12 coronelista presidido por um autointitulado "Governo Participativo" que reivindica a posse que não detém; o Estado que não domina - legal, mas não legítimo. Instaura o contrato sócio-urbano: ao definir a cidade à que cada sujeito social pertence, o leviatã está antes definindo a função social dos corpos-propriedade - assim reconhecendo os não-pertencedores, os não-sujeitos: aqueles a serem subjugados no estado de guerra.

\section{A necropolitica}

Compreende-se a necropolítica urbana como a definição socioespacial da vida: os lugares e os não-lugares; os cidadãos e os não-cidadãos; quem detém o direito à cidade, quem detém o acesso a políticas públicas - aqui entendidas como objetos de topografia social e afirmação do próprio Estado -, quem detém o acesso a infraestrutura - e quem não. Conforme coloca Mbembe (2016, p. 130), “[...] a própria estrutura do sistema de colonização e suas consequências manifesta a figura emblemática e paradoxal do estado de exceção”. A Reunião de Lançamento do Plano Diretor de Desenvolvimento Urbano de Vitória da Conquista apresenta, sob a necropolítica urbana, o utopismo urbanístico enquanto epicentro da "ocupação colonial contemporânea" (MBEMBE, 2016, p. 136), a qual “deriva sua reivindicação fundamental de soberania e legitimidade da autoridade de seu próprio relato de história e identidade” (MBEMBE,

\footnotetext{
${ }^{12}$ Episódio supostamente ocorrido entre o período de 1803 a 1806 onde, durante a ocupação do Sertão da Ressaca, convidados pelos soldados do colonizador João Gonçalves da Costa, os Mongoyó teriam sido assassinados. "Além dos confrontos diretos, os portugueses utilizaram estratégias como o oferecimento de roupas infectadas com varíola aos índios e até um embriagamento coletivo" (PMVC, 2012).
} 
2016, p. 136), no Município: O Plano Conquista 2040 é via de agnição da necropolítica em Vitória da Conquista, edificada sobre e civilizatoriamente constituída pela exceção, pelo genocídio, pelos conflitos de terra e embates de poder. O município onde a opressão se torna imaginário popular.

\section{Considerações finais}

Tratar de necropolítica a partir de uma perspectiva urbana significa atentar à política de morte subjetiva, enraizada nas dinâmicas espaciais; subentendida nos processos de hierarquização do território. Compreendem-se, aqui, articulações de políticas de Estado enquanto fatores de consolidação da segregação socioespacial; o compadrio de planos urbanísticos hipertróficos nas entrelinhas dos discursos. Percebese, a partir da própria configuração dos fenômenos de marginalização, como periferia não (mais) é um conceito espacial, mas sim um conceito de classe. O necropoder nos espaços urbanos se dá através da guerra ideológica, do litígio territorial, da luta pela terra e pela moradia: se dá através do democídio e da violação dos direitos humanos em ações de despejos, desocupações, realocações e remoções forçadas; se dá através do não-oficial institucionalizado, enraizado nas interações sociourbanas; se dá através de cidades não democráticas, mas patocráticas.

A soberania no município de Vitória da Conquista é marcada não somente pela heterogeneidade da estrutura urbana, mas pela manipulação antropofágica da memória dos sujeitos sociais enquanto ferramenta de legitimação da violência em um cenário histórico de criminalização da pobreza e especulação imobiliária. As disparidades entre os aspectos socioespaciais e socioeconômicos na morfologia territorial do município revelam a ponerologia de um núcleo urbano fragmentado, caracterizado pela estruturação hierárquica (e pública) da morte e da sistematização contrastante das especificidades urbanas. A morte se apresenta como a fundamentação do exercício de poder em um Estado regido pela exceção - onde a repressão não é mais invisível ao anseio popular, mas parte deste. Não é ao bicentenário da cidade à que o prefeito municipal se refere ao apresentar o Plano Conquista 2040 - é ao bicentenário do estado de exceção no Município. 


\section{Referências}

AGAMBEN, G. Estado de Exceção: homo sacer II, I. 2ª ed. São Paulo: Boitempo, 2004. 143p.

BARRETO, J. Reportagem A ocupação no bairro Nova Cidade, Vitória da Conquista. 10min46s. Vitória da Conquista, 08 jun. 2018. Disponível em: <https://www.youtube.com/watch?v=W6Zs071H_DI> Acesso em: 22 set. 2019.

DELEUZE, G. Post-Scriptum Sobre as Sociedades de Controle. In Conversações: 1972-1990. $1^{\text {a }}$ ed. Rio de Janeiro: Editora 34, p. 219-226, 1992.

FERRAZ, A. E. Q. O Urbano em Construção Vitória da Conquista: um retrato de duas décadas. Vitória da Conquista: Edições UESB, 2001. 202p.

FOUCAULT, M. Microfísica do Poder. $5^{\text {a }}$ ed. Rio de Janeiro: Paz e Terra, 2017. 432p.

MBEMBE, A. Necropolítica. Arte \& Ensaios: Revista Do Programa de Pós-Graduação em Artes Visuais EBA/UFRJ, 2016, n. 32. Universidade Federal do Rio de Janeiro, p. 123-151, dez. 2016. Disponível em:

<http://revistas.ufrj.br/index.php/ae/issue/view/669/> Acesso em 17 abr. 2019.

OLIVEIRA, R. F. Índios Paneleiros no Planalto da Conquista: do massacre e o (quase) extermínio aos dias atuais. Dissertação de mestrado apresentada ao Programa de Pós-Graduação em História da Faculdade de Filosofia e Ciências Humanas da Universidade Federal da Bahia, Salvador, 2012. 221p. Disponível em:

$<$ https://repositorio.ufba.br/ri/bitstream/ri/13358/1/Disserta\%C3\%A7\%C3\%A3o\%20\%20Renata\%20Ferreira\%20de\%20Oliveira.pdf>. Acesso em: 25 abr. 2019.

PEREIRA, H. G. Reunião de Lançamento do Plano Diretor de Desenvolvimento Urbano de Vitória da Conquista (PDDU). Pronunciamento de Abertura. Vitória da Conquista, Universidade Federal da Bahia, Campus Anísio Teixeira, 19 fev. 2019.

PMVC. Prefeitura Municipal de Vitória da Conquista. Lei nº 1.385/2006, de 26 de dezembro de 2006. Institui o Plano Diretor do Município de Vitória da Conquista e dá outras providências. Gabinete do Prefeito Municipal de Vitória da Conquista, Vitória da Conquista, 2006.

PMVC ,Prefeitura Municipal de Vitória da Conquista. Lei no 1.410/2007, de 05 de junho de 2007. Institui o Código Municipal do Meio Ambiente do Município de Vitória da Conquista. Gabinete do Prefeito Municipal de Vitória da Conquista, Vitória da Conquista, 2007.

PMVC, Prefeitura Municipal de Vitória da Conquista. Conflitos. 10 dez. 2012. Disponível em <http://www.pmvc.ba.gov.br/conflitos/> Acesso em 15 jul. 2019.

PMVC.Prefeitura Municipal de Vitória da Conquista. Contrato no 019-35/2018. Plano Estratégico Vitória da Conquista 2020: Etapa I - Planos Diretores de Desenvolvimento Urbano e Agência Reguladora Municipal. Secretaria de Infraestrutura Urbana. Salvador, mai. 2018. 
PMVC .Prefeitura Municipal de Vitória da Conquista. Plano Diretor de

Desenvolvimento Urbano (PDDU) de Vitória da Conquista. 19 fev. 2019a.

Publicidade.

PMVC.Prefeitura Municipal de Vitória da Conquista. PDDU. 02 ago. $2019 b$.

Disponível em <https://www.pmvc.ba.gov.br/pddu/> Acesso em 12 nov. 2019.

SANTOS, M. A Natureza do Espaço: Técnicas e Tempo. Razão e Emoção. $4^{a}$ ed. São Paulo: Editora da Universidade de São Paulo, 2006.

SANTOS, R. S. Cidades e muros: discurso da insegurança e do medo à produção de espaços exclusivos. Dissertação de mestrado apresentada ao Programa de PósGraduação em Geografia da Universidade Estadual do Sudoeste Da Bahia, Vitória da Conquista, 2019.

VILLAÇA, F. As Ilusões do Plano Diretor. $1^{a}$ ed. São Paulo: Edição do Autor, 7 ago. 2005. 